\title{
VANN, ROBERT E. (2009): MATERIALS FOR THE SOCIOLINGUISTIC DESCRIPTION AND CORPUS-BASED STUDY OF SPANISH IN BARCELONA. TOWARD A DOCUMENTATION OF COLLOQUIAL SPANISH IN NATURALLY OCCURRING GROUPS. THE EDWIN MELLEN PRESS, WALES (UNITED KINGDOM). 263 PÁGS.
}

\author{
Marta Pilar Montañez Mesas \\ (Universitat de València. Grupo Val.Es.Co.) \\ marta.montanez@uv.es
}

Este volumen recoge una breve pero valiosa muestra del español hablado en Cataluña, en concreto, dos conversaciones coloquiales que reflejan las redes sociales de dos informantes de Barcelona, transcritas mediante un sistema ortográfico para facilitar la lectura. Se trata de un corpus de unas dos horas y media de duración, que suponen el 12,5\% del total recogido, algo más de 21 horas de conversación en grupo (multiparty) y 58 horas de entrevistas lingüísticas, del año 1995. Como objetivo de partida, según el autor, este trabajo aspira a proporcionar materiales de primera mano con que documentar los usos lingüísticos de Cataluña en español y servir de ejemplo a otros investigadores para que publiquen sobre esta variedad.

Estructuralmente, el libro consta de dos bloques claramente diferenciados. Por un lado, una primera parte teórica y crítica para presentar y describir el material que ofrece y, por otro lado, el corpus propiamente dicho en la segunda parte. El apartado teórico está dedicado a tres aspectos complementarios. En primer lugar, trata ciertas cuestiones extralingüísticas, que influyen en la constitución de lo que el autor llama linguistic habitus (concepto tomado de Bourdieu, 1991) o disposición hacia una actitud lingüística u otra según el caso, adquirida en el proceso de aprendizaje de la lengua en los diferentes contextos de uso. Para ello, lleva a cabo un breve repaso de la historia de Cataluña $(\S 1)$ y de los aspectos ideológicos que intervienen en el estudio y la concepción de la variedad española en Cataluña (§2). El autor destaca la fuerte implicación ideológica que conlleva la publicación de un corpus de esta variedad, en tanto supone, frente a la idea de un 'español de Castilla defectuoso', el reconocimiento de un español regional de Cataluña, en contacto con la lengua catalana. Esta idea de variedad caracterizada por fenómenos derivados del contacto lingüístico es la que ha ido imponiéndose hasta la actualidad.

En segundo lugar, al tratarse de una obra integrada en la lingüística de corpus, se detiene en definir el concepto y aclara que este material se enmarca dentro del llamado corpus of primary data, esto es, corpus de lengua hablada complementados con metadatos e informaciones lingüísticas valiosas para que el material sirva a los fines para los que ha sido diseñado. Del mismo modo, repasa los corpus existentes tanto sobre la variedad que presenta, como sobre otra variedad afín, el español hablado en Valencia (§3), así como los rasgos lingüísticos 
concretos que se han atribuido al español en Cataluña (§4). Las características presentadas, a modo de primera cala, aparecen clasificadas por niveles lingüísticos y con indicación del autor que las ha descrito, para mostrar la importancia del trabajo de corpus como comprobación (o refutación) empírica de las intuiciones lingüísticas previas, generalmente surgidas a partir de la observación asistemática de una comunidad de habla. De todos los materiales que revisa, considera que el de Sinner (2001) es quizá el más completo, pues ha identificado características únicas del español en Cataluña que no pueden atribuirse ni al catalán ni a la influencia del castellano, evidenciando que es mucho más que un simple español de Castilla catalanizado.

En tercer lugar, atiende a los aspectos metodológicos necesarios para valorar y emplear el material que ofrece, así, describe el corpus tanto desde el punto de vista externo: recogida, digitalización y transcripción ( $(5)$, como desde el punto de vista interno: diseño y selección del corpus, descripción de los informantes y de la red social que configuran (§6). El manual se completa con una serie de tablas insertas en el cuerpo del texto que proporcionan información precisa y ordenada sobre cada uno de los contenidos recogidos.

Gran parte de los esfuerzos del autor se centran en justificar la necesidad y utilidad de los documentos que presenta, en respuesta a las sugerencias con que se concluyó en el $15^{\text {th }} \mathrm{Ger}$ man National Congress of Hispanists de 2005 -organizado por A. Wesch y C. Sinner, dos de los investigadores más interesados en esta variedad, y compiladores de sendos corpus- en el que también participaron R. Vann o M. Casanovas Catalá, quien prologa el trabajo que aquí se reseña. El autor resalta, ya desde los títulos de algunos epígrafes, el interés (casi mayor) desde fuera de España por esta variedad diatópica del español, así como la ausencia casi total de referencias a ella en los manuales canónicos de dialectología hispánica hasta los años 80 , y su tratamiento en términos más prescriptivos que descriptivos. Dicho de otro modo, muchos estudios sobre la variedad de español hablada en Cataluña se basan en la idea de corrección, es decir, la necesidad de «corregir» los errores de esta variedad de español «de Castilla» en Cataluña, en lugar de realizar una descripción dialectal de sus características propias, ya que se concibe como un 'mal español' (broken Spanish) con interferencias del catalán y no como una dialecto legítimo del español, hasta los años 90. En esta consideración subyacen razones ideológicas, en palabras de Vann, resultado del programa cultural de hegemonía del castellano y la consideración de los demás dialectos como impropios. Señala como causa adicional del olvido de esta variedad el hecho de que no existe un nombre para designarla, a diferencia de otras variedades diatópicas que sí cuentan con una designación propia. Por ello, el autor elige el término Catalan Spanish (CS) para referirse al español hablado en Cataluña, por contraste con las demás variedades.

El español hablado en Cataluña, desde el punto de vista dialectológico, se incluiría en el grupo de los dialectos innovadores (siguiendo la distinción que M. Alvar establece en el manual ya clásico de 1996, a pesar de que no lo incluye), aunque a diferencia de los meridionales -también innovadores-, que se superpusieron al árabe y al mozárabe, en Cataluña no sustituyó ninguna lengua autóctona, sino que convivió con ella, el catalán.

Por su parte, R. Vann, entre otros, desde fuera de España, ha tratado de documentar esta variedad analizando los rasgos que la distinguen en los estudios de dialectología del español, lo que le ha permitido la posibilidad de considerar que las formas del español de Cataluña que difieren del español de Castilla pueden ser socialmente significativas. Es más, el uso de estas formas de la lengua se percibe como marca o poder simbólico de resistencia, de pertenencia 
a un grupo, como signo de identidad, que en muchos casos dio lugar a una conciencia o a declaraciones de ideología nacionalista (esto explica el desarrollo de un apartado sobre nacionalismo y desarrollo de Cataluña como entidad político-económica en el primer bloque teórico de este trabajo); sin perder de vista que ciertas instituciones catalanas han favorecido el uso del catalán, lo que ha permitido su continuidad como lengua en uso junto al español en Cataluña. El autor va más allá y considera que «las formas lingüísticas del catalan Spanish pueden competir con sus correspondientes castellanas para comunicar expresiones de la cultura catalana que las formas castellanas por sí solas no transmiten (Vann, 2001, 2007, 2008)».

No obstante la descripción de unos rasgos del español de Cataluña, frente a otras variedades de la lengua española, el autor nos recuerda que toda variedad presenta, a su vez, variaciones internas, tanto horizontales (hablas y dialectos adscritos a zonas más reducidas) como verticales (favorecidas por los factores sociológicos que atañen a la sociolingüística). Ese habitus lingüístico que atribuye el autor a los hablantes se manifiesta en determinadas marcas que surgen en las distintas prácticas lingüísticas habituales; así como a las consecuencias lingüísticas a que esta disposición o hábito conducen, tal es el caso de los procesos de acomodación lingüística al interlocutor. En cualquier caso, considera imprescindible, por tanto, para comprender ese «Catalan habitus» y su correlato, el catalan Spanish, recurrir a la historia detallada de Cataluña.

Así, metodológicamente, R. Vann trabaja en el marco PEoL (Political Economy of Language), para la que la realidad social no viene dada sino que se construye, a partir de la percepción subjetiva de esa realidad. La decisión de partir de estos presupuestos obliga a Vann a dedicar todo un capítulo a la historia político-económica de Cataluña. Esto es, se centra en el tema de la construcción de la identidad catalana a partir del análisis de un corpus de lengua oral, especialmente a partir de fenómenos como los efectos del contacto de lenguas en zonas bilingües como la de Cataluña, pero no solo a nivel lingüístico, sino también las consecuencias sociales, culturales e, incluso, políticas que de ello se derivan. Por ello, concede una gran importancia a explicar la situación política española durante el siglo XX para tratar de comprender la falta de materiales y de investigaciones sobre ciertas variedades peninsulares, en concreto, sobre el catalan spanish, que es la que recoge. Solo esta necesidad de contextualizar el material que presenta en un espacio científico casi yermo en cuanto a corpus afines se refiere justifica el extenso tratamiento de cuestiones políticas que ponen en situación al lector pero que, en ocasiones, rozan lo anecdótico, en tanto no ayudan a comprender mejor los fenómenos lingüísticos del español en zonas de habla catalana o de contacto con el catalán en la actualidad. Quizá la razón se encuentre, precisamente, en el objetivo de esta obra, que no es exclusivamente lingüístico, sino que los hechos lingüísticos son un argumento más a favor de un estudio sociológico y antropológico sobre la formación de una conciencia de identidad propia en los hablantes de estas zonas. En efecto, su estudio parte de la sociología y de la sociolingüística, por lo que lo que le interesa analizar es, sobre todo, los hábitos o comportamientos lingüísticos de los hablantes, en especial, de los bilingües.

Sin embargo, aunque como un rasgo más en esa construcción de la identidad, también presta atención a los rasgos propiamente lingüísticos que caracterizan a la variedad del español en Cataluña. Así, como es sabido, los fenómenos más evidentes para detectar que se habla una variedad distinta son la pronunciación (y, especialmente, el acento) y el léxico, como expone en el capítulo 4. Este apartado resulta de gran interés para los lingüistas, y puede considerarse la verdadera aportación a la descripción dialectológica de esta variedad, 
aunque el autor lo inserta como botón de muestra y no como estudio completo y sistemático, para lo que sería necesario un corpus mayor, que es lo que, en esencia, parece reclamar con esta publicación. El autor considera que el material y los estudios que de él se deriven pueden interesar no solo a los investigadores de las áreas implicadas, sino también a la propia comunidad de habla estudiada.

Aunque el propio autor señala lo 'modesto' de esta parte publicada del corpus, también resalta el carácter inédito de materiales de esta naturaleza sobre una variedad geográfica prácticamente olvidada por la dialectología y, más aún, en la variedad diafásica que representa: la coloquial. En efecto, contamos con corpus sobre la lengua española en Cataluña en la bibliografía especializada, pero referida a la modalidad culta y obtenida mediante el sistema de entrevistas semidirigidas. La novedad e interés de este material radica en que recoge conversaciones (y no entrevistas) coloquiales (y no formales) entre miembros de dos redes sociales preexistentes en las que el investigador se integra como participante activo, grabadas en sus propios hogares y surgidas natural y espontáneamente, no preparadas ni planificadas.

Por último, como el propio autor señala en la introducción del capítulo 3, «este corpus es único entre los corpus publicados sobre español en Cataluña porque es el único que representa conversaciones coloquiales en «Catalan Spanish» entre individuos surgidas naturalmente en grupos sociales en Cataluña». Por ello, insiste en las diferencias con los demás corpus de contenido similar, sobre todo, en que son conversaciones y no entrevistas, y en que cuenta con el consentimiento previo de los informantes. En este sentido, parece una modalidad intermedia entre la entrevista semidirigida (relación no familiar entre los interlocutores, espacio marcado) y la conversación espontánea que recogen investigadores como A. Briz y el grupo Val.Es.Co. (grabación secreta, en la que la autorización es posterior, dado el vacío legal que al respecto había en España y dado que en las transcripciones se preserva el anonimato de los participantes y se modifican los topónimos y cualquier otra referencia que pueda delatar la identidad de los hablantes, que se preserva en todo caso. No obstante, las grabaciones son supervisadas por los interesados, que pueden ejercer su derecho a que no sea utilizada, ni siquiera con finalidad científica). Por el contrario, R. Vann arguye a favor de solicitar la autorización de antemano, y suple ese ‘saberse grabado' situando a los participantes en un espacio no marcado (su propio hogar), de ahí que la consideremos una opción de recogida de datos 'intermedia' (los hablantes son conscientes de que están siendo grabados pero interactúan en un lugar familiar - espacio no marcado- con miembros de su grupo o red social).

En este apartado sorprende que separe la exposición de los corpus lingüísticos del español de Cataluña (o de zonas donde se habla también alguna variedad de catalán), que expone en el capítulo 3, del repaso a los estudios basados en corpus que han servido para caracterizar esta variedad (en el capítulo 4), especialmente, porque sitúa las investigaciones de J. R. Gómez Molina (a partir del corpus PRESEEA) y de A. Briz y el grupo Val.Es.Co. en aquellos, teniendo en cuenta que sus trabajos también han servido para describir esas variedades, sobre todo, el del profesor Gómez Molina.

Además de estos, cita otros corpus de español hablado en zonas de contacto lingüístico con alguna variedad de catalán, como el de D. Azorín, que, sin embargo, no explica ni detalla en el apartado correspondiente a la descripción de los corpus (§3). Respecto del suyo, sí dedica un apartado a destacar el valor de su material y los usos que puede tener, además de servir como acicate a otros investigadores para que publiquen y proporcionen datos reales con los que estudiar esta variedad por explorar. Entre las aplicaciones que enumera, destacamos el 
uso en la clase de español, en la que, según nos indica, ha empleado estas transcripciones como recurso didáctico para el estudio de los fenómenos derivados de las lenguas en contacto (p. ej. code-switching).

La recopilación del material cuenta con particularidades que conviene precisar. Por un lado, la transcripción presenta algunas marcas significativas: el autor enriquece el sistema ortográfico con signos que representan solapamientos, aunque no emplea ningún medio para visualizar la parte solapada, solo indica que existe en una intervención. Tampoco indica cuestiones referidas a la entonación de las intervenciones o turnos, esto es, deja de lado los aspectos prosódicos tan relevantes en la lengua hablada. Por otro, reconoce que la muestra no es representativa, pues el criterio para seleccionar a los informantes no era ese (en cuyo caso el diseño del corpus debería haberse realizado teniendo en cuenta determinadas variables sociológicas y lingüísticas: edad, sexo, nivel sociocultural, lengua materna, conocimiento de las lenguas oficiales de la zona -hablante monolingüe o bilingüe-, entre otras, que sí describe para cada informante y dos miembros más de su red social, aunque no las establezca a priori como criterio para diseñar el corpus). Por el contrario, el criterio elegido por Vann es de cariz sociológico y consiste en que los hablantes formen parte de una red social preexistente, con una serie de vínculos y lazos de convivencia sólidos que, a efectos pragmáticos, lo que garantizan es un saber compartido muy intenso. Este saber compartido de los participantes coadyuva a la espontaneidad de las interacciones (aunque no la determinada por sí solo), pero no garantiza la representatividad de la muestra, rasgo deseable de todo material recopilado con fines científicos.

En cuanto al valor propiamente lingüístico de los materiales, consideramos que a pesar de haber sido grabadas en un espacio no marcado para los participantes, no se evita la laboviana paradoja del observador, más aún teniendo en cuenta que las conversaciones versan sobre el propio tema del corpus o sobre la finalidad antropológica y sociológica que el autor parece perseguir, esto es, la interacción se inicia de manera orientada (planificada), pues la persona central de la primera red social (reconocida como Mónica e identificada en la transcripción como M) dirige la actividad lingüística (que Vann considera 'conversación') hacia el tema de los hábitos lingüísticos y de cómo sus interlocutores se perciben a sí mismos como hablantes. Dicho de otro modo, se trata de un acto directivo (casi siempre formulado a modo de pregunta) que trata de obtener unos determinados datos, generalmente más sociológicos que lingüísticos, y que guían y reconducen las intervenciones. En este sentido, el corpus presentado por Vann se encontraría más próximo a la metodología del PRESEEA, con la diferencia, eso sí, de que el investigador se integra (o trata de integrarse) en la red social investigada para minimizar la distancia comunicativa y favorecer una cierta relación de proximidad (si empleamos los factores definidos por A. Briz y el grupo Val.Es.Co.) o de familiaridad entre los interlocutores y de implicación emocional (si optamos por los rasgos descritos por P. Koch y W. Oesterreicher).

Por todo lo anterior, se podría cuestionar la espontaneidad que Vann atribuye a estas conversaciones, hecho que se observa, entre otros fenómenos, en la extensión de las intervenciones de $\mathrm{M}$ o de $\mathrm{S}$, centro de la segunda red social representada, sensiblemente más largas, por lo general, que las de sus interlocutores, pues reorienta la 'conversación' cuando los demás participantes decaen o agotan el tema planteado en la intervención anterior. Una de las premisas para garantizar la espontaneidad de la muestra es que el participante observador no interfiera en el desarrollo de la interacción, esto es, que no contribuya más de lo necesario 
para no alterar la progresión natural de las intervenciones, que pueden configurar una conversación o constituir meros intercambios que no llegan a configuran una secuencia dialógica completa ni una conversación (en términos valesquianos de unidades y de estructura de la conversación).

Otro de los rasgos que definen la conversación espontánea es el tema, que cambia libremente y que no suele estar determinado de antemano (aunque los participantes pueden tener interés en contar algo, los temas surgen a lo largo de la interacción, no se concretan previamente). En ese sentido, nos parece curioso que los participantes inicien la interacción, a partir de la indicación explícita de M, comentando su propia conciencia como hablantes, pues casi se trata de un discurso metalingüístico, en tanto hablan sobre cómo hablan y sobre cómo se sienten como hablantes. Obviamente, sería improbable captar la temática de esta interacción en una conversación espontánea prototípica, en la que la temática predominante no es especializada (lo cual no es óbice para que puedan aparecer secuencias en las que se traten temas especializados y el registro sea menos informal o, como en otros casos, se traten informal o coloquialmente temas especializados, por ejemplo, entre investigadores con un saber compartido muy acusado). La aparición de este tema solo se explica por el propio interés sociológico y antropológico del análisis de este material. A objetivos científicos distintos, materiales y planteamientos metodológicos distintos. No siempre es coherente comparar los contenidos de los distintos corpus ni los trabajos que de ellos se derivan, puesto que los fines que unos y otros persiguen no siempre son coincidentes.

En definitiva, el material que aquí se presenta y los datos que de él se ofrecen están condicionados por el status quaestionis sobre esta variedad de español, configurado por factores no exclusivamente lingüísticos. Para R. Vann, en efecto, la historia lingüística del español en Cataluña está marcada por la presencia constante de diversos aspectos ideológicos que han condicionado el conocimiento científico de ciertas variedades del español, entre ellas, el español hablado en zonas de contacto de lenguas, en este caso, con el catalán. La carga ideológica se refleja también en la identidad lingüística de los hablantes, en los casos en que favorece la posibilidad de un cambio de lengua (habitus), que suele plasmarse en un intento de acomodación lingüística al interlocutor, sobre todo, en situaciones comunicativas informales como las que nos ofrece este corpus. 